\title{
Solar Coatings Based on Ag Infrared Reflector with High Stability at Medium and High Temperature
}

\author{
Salvatore Esposito ${ }^{1, *}$, Antonio D'Angelo ${ }^{1}$, Claudia Diletto ${ }^{1}$, Antonio Guglielmo ${ }^{1}$, Michela Lanchi ${ }^{2}$ \\ and Gabriella Rossi ${ }^{1}$ \\ 1 Portici Research Centre, ENEA, P.le E. Fermi 1, 80055 Portici, Italy; antonio.dangelo@enea.it (A.D.); \\ claudia.diletto@enea.it (C.D.); antonio.guglielmo@enea.it (A.G.); gabriella.rossi@enea.it (G.R.) \\ 2 Casaccia Research Centre, ENEA, Via Anguillarese 301, 00123 S. Maria di Galeria, Italy; \\ michela.lanchi@enea.it \\ * Correspondence: salvatore.esposito@enea.it; Tel.: +39-081-772338
}

check for updates

Citation: Esposito, S.; D'Angelo, A.; Diletto, C.; Guglielmo, A.; Lanchi, M.; Rossi, G. Solar Coatings Based on Ag Infrared Reflector with High Stability at Medium and High Temperature. Energies 2021, 14, 5910. https:// doi.org/10.3390/en14185910

Academic Editor: Bashir A. Arima

Received: 26 July 2021

Accepted: 13 September 2021

Published: 17 September 2021

Publisher's Note: MDPI stays neutral with regard to jurisdictional claims in published maps and institutional affiliations.

Copyright: (c) 2021 by the authors. Licensee MDPI, Basel, Switzerland. This article is an open access article distributed under the terms and conditions of the Creative Commons Attribution (CC BY) license (https:// creativecommons.org/licenses/by/ $4.0 /)$.

\begin{abstract}
The manufacturing of thermally stable solar coatings with high photo-thermal performance represents a key factor for the further deployment of the CSP technology. Since 2005, ENEA has been developing solar coatings suitable for medium and high temperature applications based on the technology of double nitride cermet, by employing silver and tungsten as infrared reflectors, respectively. Thanks to the high infrared reflectance of silver, the corresponding coatings have better optical performance than those with tungsten; however, the high diffusivity of silver compromises its use at high temperature. In order to improve the structural and chemical stability at medium and high temperature of coatings based on silver, this infrared reflector was placed between compact and uniform layers of metal and cermet manufactured by using high-energy and fast deposition processes. In particular, an Unbalanced Magnetron cathode was adopted to promote an ion-assisted deposition process that improved uniformity and compactness of the metal and cermet films. The new coating shows no photo-thermal parameters degradation after 25 years of service at the operating temperature of $400{ }^{\circ} \mathrm{C}$, while its photo-thermal conversion efficiency decreases by only $1.5 \%$ after 25 years of service at an operating temperature of $514{ }^{\circ} \mathrm{C}$.
\end{abstract}

Keywords: solar coating; infrared reflector; cermet; thermal stability; durability; accelerated test

\section{Introduction}

Concentrating Solar Power (CSP) technology can be considered as a mature technology for large-scale renewable energy production [1,2], destined to significantly contribute to the ambitious decarbonization objective set by the European Green Deal of greenhouse gas emissions reduction of at least $50 \%$ by 2030 and environmental neutrality by 2050 . Moreover, this technology can play an important role in allowing high shares of solar PV and wind in the energy mix, thanks to its capability to provide dispatchable renewable heat/electricity. In the last decade, the cost of electricity from concentrating solar power has fallen by $68 \%$ and the installation costs of a CSP plants have been substantially halved [3]. However, the CSP economic feasibility needs to be further addressed by improving the efficiency and durability of each plant component of concentrating solar plants, since it is generally agreed upon that higher components' efficiency for longer times (at least 25 years) represents a crucial requirement for CSP economical sustainability [4].

In Concentrated Solar Thermal (CST) technology, the solar field, constituted of multiple solar collectors, represents the distinctive, and the costliest, element. The collectors intercept the incoming radiation and concentrate it on the receiver surface, where a heat transfer fluid absorbs the concentrated radiation in the form of sensible heat. The sensible heat can then be stored and converted into electricity or supplied as thermal energy to endothermic processes. In linear focusing CST technology, two types of collectors are currently used: parabolic trough collector (PTC) and linear Fresnel collector (LFC) [5-10]. 
In these systems, mirrors concentrate the solar energy on tube receivers covered with a spectrally selective absorber coating characterized by high solar absorptance $\left(\alpha_{\mathrm{s}}\right)$ and low thermal emittance $\left(\varepsilon_{\mathrm{th}}\right)$ at the operating temperature, in order to maximize the energy absorption and minimize the heat losses toward the ambient.

The solar absorber coating can be considered as a strategic element of solar receivers, since the efficiency, durability and economic feasibility of a solar plant strongly depend on its photo-thermal conversion efficiency and thermal stability. An ideal spectrally selective absorber coating should have zero reflectance in the visible region and unit reflectance in the infrared region. In order to obtain this shape of reflectance, an accurate design of the absorber coating is required. The use of metal-ceramic (cermet) composite coating is one of the most widely approach to obtain spectrally selective absorber coatings for medium and high temperature applications [11-14]. Among the deposition technologies of the cermet-based coatings, Magnetron sputtering has proved to be particularly suitable to fabricate absorber coatings with the target characteristics [15-25]. This technology allows controlling the size and quantity of the metallic and ceramic particles inside the composite materials with high accuracy. Furthermore, this technology is particularly suitable to industrial production thanks to its capability to deposit on large area at a high rate and low cost $[26,27]$.

Since 2005, ENEA has been developing and patenting solar absorber coatings suitable for medium $\left(400{ }^{\circ} \mathrm{C}\right)$ and high $\left(550{ }^{\circ} \mathrm{C}\right)$ temperature applications, based on the technology of double nitride cermet $[26,28]$. These coatings have infrared reflector of silver (Ag) or tungsten $(\mathrm{W})$, depending on the applicative temperature, covered by a graded multilayer cermet of tungsten nitride and aluminum nitride (WN-AlN) and, lastly, by an antireflection filter $(\mathrm{AR})$ of aluminum nitride $(\mathrm{AlN})$ and silica $\left(\mathrm{SiO}_{2}\right)$ [28]. The $\mathrm{Ag}$ infrared reflector allows maintaining the thermal emissivity of the absorber coating low, thanks to its high reflectance in the infrared region. However, the high diffusivity of $\mathrm{Ag}$ atoms undermines the structural and chemical stability of the coating, compromising its use at high temperatures for a long time. Differently, coatings with $\mathrm{W}$ as infrared reflector exploit the low diffusivity of this metal to ensure negligible degradation of the photo-thermal performance at high temperature for long time. However, as a drawback, the thermal emissivity of the absorber coating is higher, since the reflectance of $\mathrm{W}$ is lower than the Ag one in the infrared region. Hence, Ag has proven reliability for medium-temperature applications, and W for hightemperature ones [26]. The ENEA technology for solar coating manufacturing was acquired by Archimede Solar Energy (ASE) Company to produce and commercialize two typologies of receiver tube depending on the application temperature: the first one is a receiver tube with an $\mathrm{Ag}$ infrared reflector suitable for application up to $400{ }^{\circ} \mathrm{C}$; the second has $\mathrm{W}$ as an infrared reflector, developed for applications up to $550{ }^{\circ} \mathrm{C}$. Both receiver tubes are currently installed on demonstrative/commercial parabolic trough plants (AKESAI plant in China, DUBA 1 plant in Saudi Arabia, MATS plant in Egypt [29]).

In the last 20 years, the research on CSP was partly focused on the increase of the plants' operating temperatures in order to enhance the heat-to-electricity conversion efficiency and to reduce the electricity cost [30-33]. Many efforts have been made to develop selective absorbing coatings with good photo-thermal performance and long-term thermal stability at higher temperatures [28,34-42]. The aim of the present work is to increase the long-term thermal stability at a higher temperature of the previous ENEA solar absorber coating with $\mathrm{Ag}$ as infrared reflector, maintaining its excellent photo-thermal performance. For this purpose, a new coating, with an Ag infrared reflector and a graded multilayer cermet of W-AlN, was designed and manufactured by using high-energy and fast deposition processes. In detail, the growth of Ag infrared reflectors with improved thermal stability was promoted by implementing efficient surface pre-treatments of stainless steel (SS) substrate and placing the Ag layer between more compact and uniform layers of W and W-AlN than those of W and WN-AIN of the previous ENEA's double-nitride cermet technology [26,28]. The coating was finally completed by depositing an additional antireflection filter based 
on $\mathrm{AlN}$ and $\mathrm{SiO}_{2}$ ceramics in combination with a low Metallic Volume Fraction (MVF) cermet material.

An investigation method developed by ENEA [43] was applied to estimate the longterm thermal stability of the new solar absorber coating and that of the coating based on the WN-AlN cermet [28]. This method predicts the lifetime of the manufactured solar coatings by accelerated ageing tests conducted at temperatures above the operating one, with the aim of experimentally simulate the evolution of the coating over the years. Therefore, the coating was exposed to fast, but not unrealistic, degradation mechanisms. The temperatures of the accelerated tests were properly selected to activate the same degradation mechanisms that are associated to the real working conditions of the coating.

\section{Materials and Methods}

Metallic, ceramic and cermet films of the solar absorber coating were deposited by a sputtering technique by using a planar Magnetron sputtering system composed of a process chamber and a load lock chamber. In the load lock chamber, both plasma and heating pre-treatments can be performed on substrates. In the process chamber, six cathodes can be arranged in pairs on two opposite sides. Specifically, a Standard Magnetron cathode in DC (Direct Current) sputtering mode was employed for Ag deposition, whereas a Gencoa Unbalanced Magnetron cathode in DC sputtering mode was used to deposit the adaptive layer of $\mathrm{W}$ and the $\mathrm{W}$ metallic component of the multilayer cermet $\mathrm{W}-\mathrm{AlN}$. The first adaptive layer of W was grown on pre-treated SS substrate to improve adhesion as well as structural and chemical stability of the Ag layer [44]. A high quality W film with a more compact structure and lower defects than previous ones was obtained by using in place of a standard Magnetron cathode [28] the Unbalanced Magnetron cathode. This cathode is designed with a magnetic pole on the external perimeter strengthened with respect to the central pole. With this configuration, the unbalanced magnetic array changes the magnetic field shape, allowing the release of some plasma electrons towards the substrate, and thus, providing ion assistance during the coating deposition. On the deposited Ag layer, a W-AlN multilayer cermet was placed with the following purposes: to absorb solar radiation, stabilize the Ag infrared reflector and block the Ag diffusion in the neighboring layers. Additionally, in this case, a more compact and uniform multilayer cermet of W-AlN than that of WN-AlN of the previous ENEA's double-nitride cermet technology was obtained by using the same Unbalanced Magnetron cathode as the one adopted for $\mathrm{W}$ deposition in place of a standard Magnetron [28]. Two Dual Magnetron cathodes were used to deposit $\mathrm{AlN}$ and $\mathrm{SiO}_{2}$ by $\mathrm{MF}$ (Medium Frequency) reactive sputtering technology in transition mode [45]. In particular, the Dual Magnetron cathode for the AlN deposition was arranged on the opposite side of the Unbalanced Magnetron cathode in order to carry out the W-AlN cermet films in co-sputtering mode. The deposition plant is also equipped with a spectroscopic PEM system (PLASUS GmbH Company equipment, Mering, Germany) characterized by six independent spectrometer channels. The complete spectrum of the plasma light emission is acquired continuously by optical fibers in the wavelength range 200-1100 nm. Each Dual Magnetron cathode is monitored by two optical fibers, one fiber for each plasma region facing the two targets of the Dual Magnetron cathode. The control function of the PEM system is performed through a proportional-integral-derivative (PID) controller which allows maintaining unchanged target conditions during the reactive sputtering process. This control system makes possible the deposition of all ceramic components of the coating by means of reactive Magnetron sputtering technology in transition mode. A high deposition rate of the coating was guaranteed by using the DC sputtering technology to deposit all metallic components and the reactive Magnetron sputtering technology in transition mode with MF supply to grow all ceramic components [46].

The Ag infrared reflector was deposited on SS planar substrates fixed inside housings on the external surface of a SS tube $(\mathrm{L}=60 \mathrm{~mm}, \mathrm{D}=7 \mathrm{~mm})$. This tube-holder moves back and forth with respect to the targets with an adjustable sweep velocity and rotates with a spin velocity that is also adjustable. The pre-treatment was performed through 
the heating of SS substrate by means of thermal radiation from three resistances warmed at a temperature of about $500{ }^{\circ} \mathrm{C}$, followed by an ionic etching performed in argon (Ar) plasma at $2.0 \mathrm{~Pa}$ of pressure and by applying $3 \mathrm{kV} \mathrm{DC}$ voltage to the tube-holder. After pre-treatment, the tube-holder was transferred in the process chamber to deposit the adaptive layer of $\mathrm{W}$. This layer was deposited with $13.33 \mathrm{~W} / \mathrm{cm}^{2}$ power density applied to the cathode and at Ar pressure of $0.4 \mathrm{~Pa}$. For this deposition, the spin velocity of the tube-holder was fixed at $15 \mathrm{rpm}$ while the carrier sweep velocity was fixed at $50 \mathrm{~cm} / \mathrm{min}$. Hence, the Ag infrared reflector was grown with $4.39 \mathrm{~W} / \mathrm{cm}^{2}$ power density applied to the cathode and at an Ar pressure of $1 \mathrm{~Pa}$. The spin and sweep velocities were fixed at $30 \mathrm{rpm}$ and $200 \mathrm{~cm} / \mathrm{min}$, respectively. The refractive index $\mathrm{n}$ and the extinction coefficient $\mathrm{k}$ of the Ag infrared reflector were estimated with the ellipsometric technique using a Variable Angle Spectroscopic Ellipsometer (VASE) equipment of J.A. Woollam Company (Lincoln, NE). This instrument enables to operate in the wavelength range $0.25-2.50 \mu \mathrm{m}$.

Four W-AlN cermet samples were deposited and optically characterized for the design of the graded multilayer cermet of the solar coating. To this aim, these samples were grown on glass planar substrates fixed using the same housing on the tube-holder. The cermet samples were grown in $\mathrm{Ar}+\mathrm{N}_{2}$ plasma, moving and rotating the tube-holder back and forth with respect to the $\mathrm{Al}$ and $\mathrm{W}$ targets. The sweep and spin velocities were fixed at $100 \mathrm{~cm} / \mathrm{min}$ and $60 \mathrm{rpm}$, respectively. A total Ar flow equal to $400 \mathrm{sccm}$ was injected in the process chamber from the gas-rings around the frontal $\mathrm{Al}$ and $\mathrm{W}$ targets $(200 \mathrm{sccm}$ for the side). The $\mathrm{N}_{2}$ gas was introduced in the process chamber from the gas-ring around the Al targets and the flow was controlled by the PEM system. Process pressure was fixed at about $1 \mathrm{~Pa}$. These four samples were deposited by applying a constant power density of $5.17 \mathrm{~W} / \mathrm{cm}^{2}$ to the $\mathrm{Al}$ targets, whereas the power densities applied to the $\mathrm{W}$ target are reported in Table 1. Each sample in this table is classified as a function of the metallic volume fraction included in the cermet film.

Table 1. Power densities at the $\mathrm{W}$ target corresponding to each of the four deposited W-AlN cermet samples.

\begin{tabular}{|c|c|}
\hline $\begin{array}{c}\text { Cermet } \\
\text { (Metal Volume Fraction) }\end{array}$ & $\begin{array}{l}\text { Power Density } \\
\left(\mathrm{W} / \mathrm{cm}^{2}\right)\end{array}$ \\
\hline Very High (VHMVF) & 8.89 \\
\hline High (HMVF) & 6.67 \\
\hline Medium (MMVF) & 4.44 \\
\hline Low (LMVF) & 2.22 \\
\hline
\end{tabular}

A new AR filter was designed for the solar coating by using $\mathrm{AlN}$ and $\mathrm{SiO}_{2}$ ceramics in combination with a low MVF cermet material. Therefore, a fifth cermet sample, classified as Very Low MVF (VLMVF), was grown on glass planar substrates by using the same deposition parameters as the ones adopted for the other cermet samples, except for the power densities applied to the $\mathrm{W}$ target that was $0.89 \mathrm{~W} / \mathrm{cm}^{2}$. This cermet was optically characterized and used to select the low MVF cermet material of the AR filter design. The AlN layer of the AR filter was grown on glass planar substrates in $\mathrm{Ar}+\mathrm{N}_{2}$ plasma, moving and rotating the holder in front of the Al targets with sweep velocity of $100 \mathrm{~cm} / \mathrm{min}$ and spin velocity of $60 \mathrm{rpm}$. A total Ar flow equal to $400 \mathrm{sccm}$ was injected in the process chamber through the gas-rings around the frontal $\mathrm{Al}$ and $\mathrm{W}$ targets (200 sccm for the side) in order to maintain the same gas flow configuration as the one of the W-AlN cermet deposition. The $\mathrm{N}_{2}$ gas was introduced in the process chamber from the gas-ring around the $\mathrm{Al}$ targets and the flow was controlled by the PEM system. Process pressure was fixed at about $1 \mathrm{~Pa}$, while the power density applied to the $\mathrm{Al}$ targets was $5.17 \mathrm{~W} / \mathrm{cm}^{2}$. The $\mathrm{SiO}_{2}$ layer of the AR filter was grown on glass planar substrates in $\mathrm{Ar}+\mathrm{O}_{2}$ plasma moving and rotating the holder in front of the silicon ( $\mathrm{Si}$ ) targets with the same sweep and spin velocities as the ones used to deposit the AlN film. A total Ar flow of $200 \mathrm{sccm}$ was injected in the process chamber from the gas-ring around the $\mathrm{Si}$ targets. The $\mathrm{O}_{2}$ gas was introduced 
in the process chamber from the gas-ring around the Si targets and the flow was controlled by the PEM system. Process pressure was fixed at about $1 \mathrm{~Pa}$, while the power density applied to the Si targets was $3.88 \mathrm{~W} / \mathrm{cm}^{2}$.

The thickness of each ceramic and cermet samples was mechanically measured on films grown on glass substrate using a Tencor P-7 surface profiler.

Optical reflectance and transmittance measurements of ceramic and cermet samples were performed by a UV-Vis-NIR spectrophotometer, using a double-beam Perkin-Elmer mod. Lambda 950 instrument equipped with a $15 \mathrm{~cm}$ diameter integrating sphere. The refractive index $\mathrm{n}$ and the extinction coefficient $\mathrm{k}$ of each sample were estimated by an inversion method applied to the experimental reflectance and transmittance data [47] and used to create a database. The database was completed with the Ag optical parameters and imported in Essential Macleod (Version 9.9.457/Manufacturer Thin Film Center Inc., Tucson, AZ, USA), a commercial software for the optical analysis of multilayer structures, to design the solar coating. Hence, the solar coating was fabricated and its optical reflectance was still measured by the Lambda 950 using the integrating sphere.

This spectrophotometer was also used to measure the high specular reflectance of the SS/W / Ag multilayer by a directional absolute reflectance "IV" accessory, designed to provide the highest possible accuracy for specular reflectance measurements of highly reflective materials. The optical reflectance of the SS/W/Ag multilayer was obtained by adding the specular reflectance to the diffuse reflectance measured by the same instrument with the integrating sphere.

Finally, the long-term thermal stability of the new solar absorber coating was estimated and compared with that of the coating based on the WN-AlN cermet [28]. A procedure for accelerated life testing of absorber coatings was developed within the framework of the working group, "Materials in Solar Thermal Collectors" of the International Energy Agency-Solar Heating and Cooling Program [48-53]. The procedure was formulated as a standard and submitted to the International Organization for Standardization (ISO). The proposed standard has been applied to examine the long-term stability of absorber coatings used in flat-plate collectors for domestic hot water systems [48-53]. Unfortunately, a standard procedure has not been formalized yet to evaluate the long-term thermal stability of solar collectors for CSP plants. Moreover, the methodology for durability test procedures and the service lifetime prediction methods adopted by the leading manufacturers of receiver tubes have not been diffused and the scientific literature on the topic is lacking. Thus, in order to estimate the degradation of a solar absorber coating for CSP plants, ENEA has developed an investigation method that derives from the main guidelines of the standard procedure for assessing the thermal stability of hot water systems [43]. Specifically, six samples (two samples for each test), having the same coating, were subjected to three accelerated ageing tests consistent of three separated treatments, by using a programmable oven able to operate up to $1000^{\circ} \mathrm{C}$ at a pressure of $2 \times 10^{-2} \mathrm{~Pa}$. The first test was carried out at $620^{\circ} \mathrm{C}$ for a total duration of $1128 \mathrm{~h}$, the second one at $650{ }^{\circ} \mathrm{C}$ for a total duration of $320 \mathrm{~h}$ and, finally, the last one at $690^{\circ} \mathrm{C}$ for a total duration of $96 \mathrm{~h}$. Solar absorptance and hemispherical emittance of the solar coating were calculated after every heat treatment by using the spectral reflectance measured by the Lambda 950 and by an infrared spectrometer at room temperature. The infrared reflectance was measured by a FTIR (Fourier Transform Infra-Red) spectrometer in the wavelength range 1.7-17 $\mu \mathrm{m}$, by using a BRUKER mod. INVENIO X (Ettlingen, Germany) equipped with an MCT detector and a $7.5 \mathrm{~cm}$ diameter integrating sphere, coated with diffuse reflecting gold. The instrumental accuracy in the measurement of $\alpha_{\mathrm{s}}$ and $\varepsilon_{\text {th }}$ was equal to $\pm 0.05 \%$ and $\pm 0.14 \%$, respectively.

\section{Results and Discussion}

The experimental work described in this article deals with the improvement of the structural and chemical stability at medium and high temperature of the solar coatings with Ag as infrared reflector previously developed by ENEA. To this purpose, efficient surface pre-treatments of SS substrates were implemented and an Ag layer was placed between 
layers of W and W-AlN, characterized by higher compactness and homogeneity than those of $\mathrm{W}$ and $\mathrm{WN}-\mathrm{AlN}$ of the double-nitride cermet technology previously developed by ENEA $[26,28]$. An Unbalanced Magnetron cathode in place of a standard Magnetron was adopted to promote an ion-assisted deposition process that improved uniformity and compactness of the films above and below the Ag layer.

The multilayer structure of the optimized solar coating with improved thermal stability is composed of the following layers:

$\mathrm{SS} / \mathrm{W} / \mathrm{Ag}$ /graded cermet (W-AlN)/AR filter (AlN, low MVF cermet, $\mathrm{SiO}_{2}$ ).

In this section, the procedure developed to deposit each single layer useful for the design of the solar coating is described. Once the samples were manufactured, they were optically characterized and the refractive indexes and extinction coefficients were used to create a database to be employed for the design of the solar coating. The resulting design consisted of a sequence of layers with assigned thickness values and with a specific metal content profile of the graded multilayer cermet. Hence, the new coating was manufactured according to this design and optically characterized to evaluate $\alpha_{\mathrm{s}}$ and $\varepsilon_{\mathrm{th}}$. Finally, the solar coating was subjected to accelerated ageing tests in order to estimate its structural and chemical stability.

\subsection{Ag Infrared Reflector}

The Ag infrared reflector was deposited on a SS substrate according to the operative conditions specified in the "Materials and Methods" section. In particular, a $120 \mathrm{~nm}$ thick layer of $\mathrm{Ag}$ was deposited on a $120 \mathrm{~nm}$ thick layer of W.

The optical characterization of the Ag layer was performed by the ellipsometric technique applied to the Ag layer deposited on SS/W structure. In this way, the optical estimation procedure was applied to the actual growth condition of the Ag layer during the solar coating fabrication. The spectral $n$ and $k$ values of the Ag layer deposited on SS/W structure were immediately determined by applying the equation of the pseudodielectric function [54], which coincides with the actual dielectric function, with the metal thickness being sufficiently large to allow neglecting optical reflection at the W/Ag interface. In Figure 1a, the optical parameters of the Ag layer are shown. These optical parameters were imported in Macleod to simulate the spectral reflectance of the Ag layer; this simulated curve was compared with the experimental spectral reflectance measured by spectrophotometric technique. In Figure 1b, this comparison is reported. As can be seen, the good agreement between the simulated and experimental curve proves the accuracy of $\mathrm{n}$ and $\mathrm{k}$ estimation performed by the ellipsometric technique.

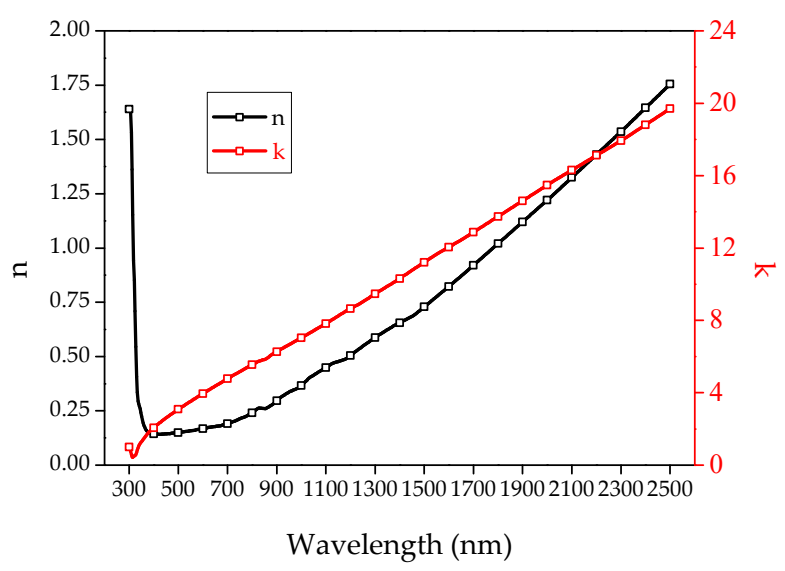

(a)

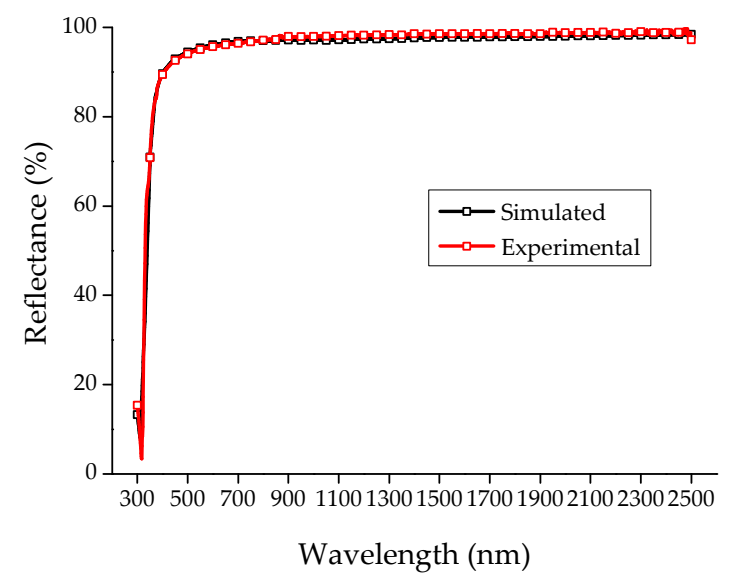

(b)

Figure 1. Optical parameters and reflectance of the Ag layer deposited on the SS/W structure. (a) Refractive index $n$ and extinction coefficient k; (b) Comparison between the simulated (dark) and the experimental (red) spectral reflectance of the Ag layer. 


\subsection{W-AlN Cermet}

This section deals with the experimental activity carried out to develop the deposition process of cermet samples. Reactive sputtering technology in transition mode was employed in order to grow the AlN ceramic component of the cermet samples. This technology offers the possibility to grow ceramic materials at high deposition rate but with the drawback of major complexity of the deposition processes, with the target conditions being extremely sensitive to the quantity of reactive gas injected in the process chamber. Therefore, a PEM system is employed to verify the sputtering process conditions in the deposition chamber through the control and the management of emission spectral line intensity of any excited species involved in the plasma. To tune the PEM system, the intensity of the emission spectral line of the element selected as representative of the target conditions is acquired, increasing and then decreasing the reactive gas flow injected in the process chamber. The obtained curve, named the hysteresis curve, is used by the PEM system to manage the quantity of reactive gas introduced in the chamber in order to maintain unchanged the intensity of the emission spectral line of the controlled element during the deposition process.

Regarding the cermet deposition, the process developed by ENEA employs the same power density to grow the ceramic component and different power densities to deposit the metallic component. The $\mathrm{N}_{2}$ gas was introduced in the process chamber from the gas-ring around the Al targets and controlled by the PEM system in order to maintain unchanged the $\mathrm{Al}$ emission spectral line during the process, with this line having high intensity and sensitivity to target condition variations. Since the hysteresis phenomenon can be mitigated by overpumping the process chamber $[45,55,56]$, a high Ar flow (400 sccm) was injected in the chamber during the cermet deposition. The resulting hysteresis curve was characterized by a slow variation of $\mathrm{Al}$ emission intensity from metallic to poisoned region as a function of the $\mathrm{N}_{2}$ flow. In the ENEA process, all ceramic components of cermet samples are deposited with the same voltage at the $\mathrm{Al}$ targets; this reference voltage is selected by depositing the ceramic component alone and setting the $\mathrm{Al}$ emission intensity on the hysteresis curve so as to obtain the expected optical properties for the ceramic material [46]. The hysteresis curve of $\mathrm{Al}$ emission intensity was acquired at a high Ar flow $(400 \mathrm{sccm})$ and several values of intensity were selected along this curve to deposit AlN samples with different optical properties. Each deposited sample was optically characterized and the refractive index $n$ and the extinction coefficient $k$ were estimated. The AlN sample deposited at 31,000 Counts (Cts), which is the unit used by PEM to measure the intensity of emission spectra, was $143 \mathrm{~nm}$ thick and had optical parameters with trends characteristic of a ceramic material with a good transparency in correspondence to the solar spectrum, as shown in Figure 2. In this case, the voltage at the $\mathrm{Al}$ targets during the deposition process was $326 \mathrm{~V}$.

The next step was the detection of the Al emission intensity on the hysteresis curve at which to deposit the ceramic component of each cermet sample. This working point was detected by varying the flow of $\mathrm{N}_{2}$ until the voltage at the $\mathrm{Al}$ targets was equal to the reference voltage [46]. In Table 2, the working points of the four cermet samples for the design of the graded multilayer cermet are reported. It is interesting to observe that the $\mathrm{Al}$ emission intensities associated to the working points increase with the power density applied to the $\mathrm{W}$ target because the plasma facing the $\mathrm{W}$ target contributes to ionize the $\mathrm{Al}$ atoms sputtered in the plasma by the $\mathrm{Al}$ targets. As an example, Figure 3 reports the hysteresis curves of the Al spectral line acquired to deposit the cermet samples with VHMVF and LMVF. This figure also shows that the acquired curves are characterized by a slow transition from metallic to poisoned region thanks to the deposition process conditions. 


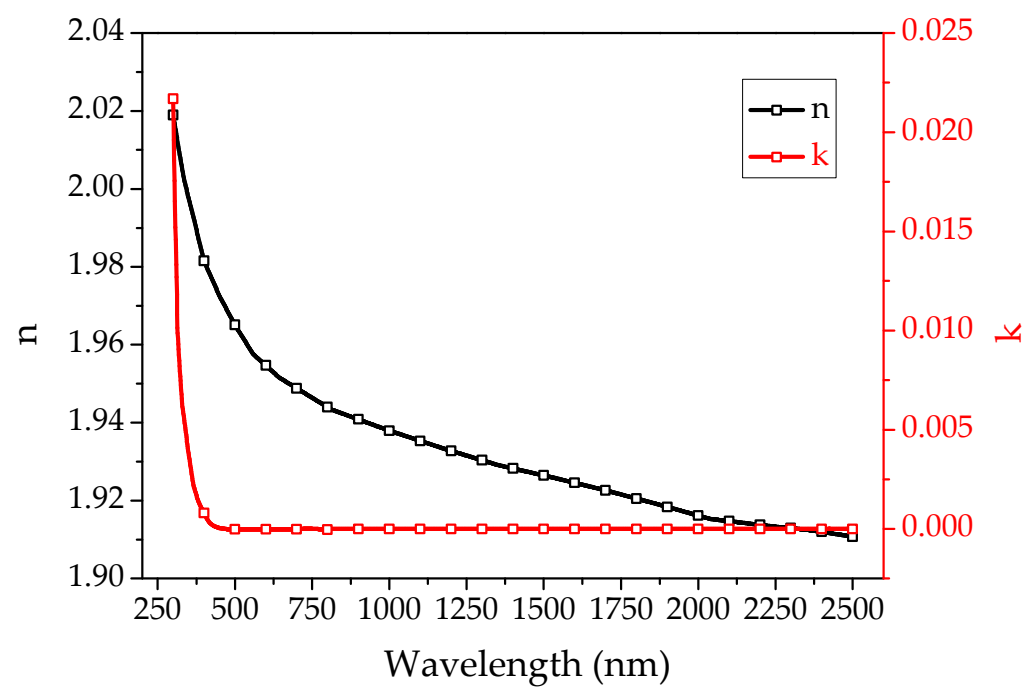

Figure 2. Refractive index $\mathrm{n}$ and extinction coefficient $\mathrm{k}$ of AlN.

Table 2. Working points of the four cermet samples used for the design of the graded multilayer cermet.

\begin{tabular}{ccc}
\hline $\begin{array}{c}\text { Cermet } \\
\text { (Metal Volume Fraction) }\end{array}$ & $\begin{array}{c}\text { Working Point } \\
\text { (Cts, sccm) }\end{array}$ & $\begin{array}{c}\text { Voltage at the Al Targets } \\
\text { (V) }\end{array}$ \\
\hline Very High (VHMVF) & $(38.000,30.5)$ & 329 \\
High (HMVF) & $(35.000,30.4)$ & 327 \\
Medium (MMVF) & $(32.000,30.9)$ & 325 \\
Low (LMVF) & $(29.000,30.7)$ & 324 \\
\hline
\end{tabular}

The four cermet samples were deposited and optically characterized Table 3 reports the corresponding evaluated thickness, whereas Figure 4 shows the optical parameters estimated by inversion method. Table 3 and Figure 4 also report the thickness and the optical parameters of the VLMVF cermet sample used to select the low MVF cermet material of the AR filter design. As can be seen in Figure 4, the power densities selected for the solar coating design provide cermet materials with optical properties well distributed in a wide range and, therefore, suitable for the design of a graded multilayer cermet. An interpolation method was applied to estimate the optical parameters of cermet materials having intermediate MVF values. A sampling step of the W power density equal to 0.44 $\mathrm{W} / \mathrm{cm}^{2}$ was used to interpolate the optical parameters of the intermediate cermet materials included between the VHMVF and the VLMVF cermet materials.

Table 3. Thickness evaluations of the W-AlN cermet samples.

\begin{tabular}{cc}
\hline $\begin{array}{c}\text { Cermet } \\
\text { (Metal Volume Fraction) }\end{array}$ & $\begin{array}{c}\text { Thickness } \\
\text { (nm) }\end{array}$ \\
\hline Very High (VHMVF) & 47.0 \\
High (HMVF) & 54.5 \\
Medium (MMVF) & 61.6 \\
Low (LMVF) & 57.8 \\
Very Low (VLMVF) & 52.8 \\
\hline
\end{tabular}




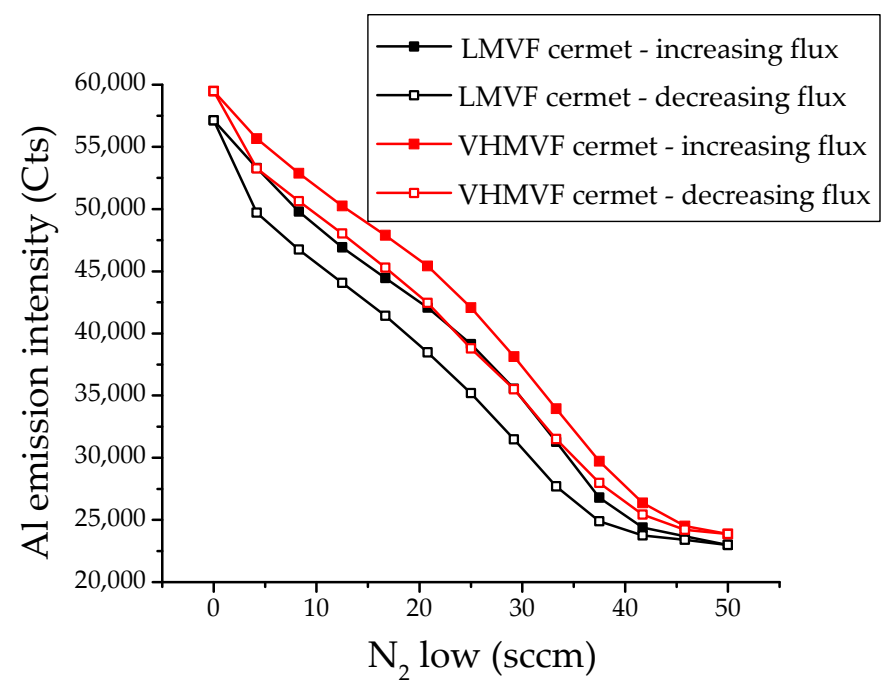

Figure 3. Intensities of the emission spectral line of $\mathrm{Al}$ inside the plasma acquired to deposit the cermet samples with VHMVF and LMVF.

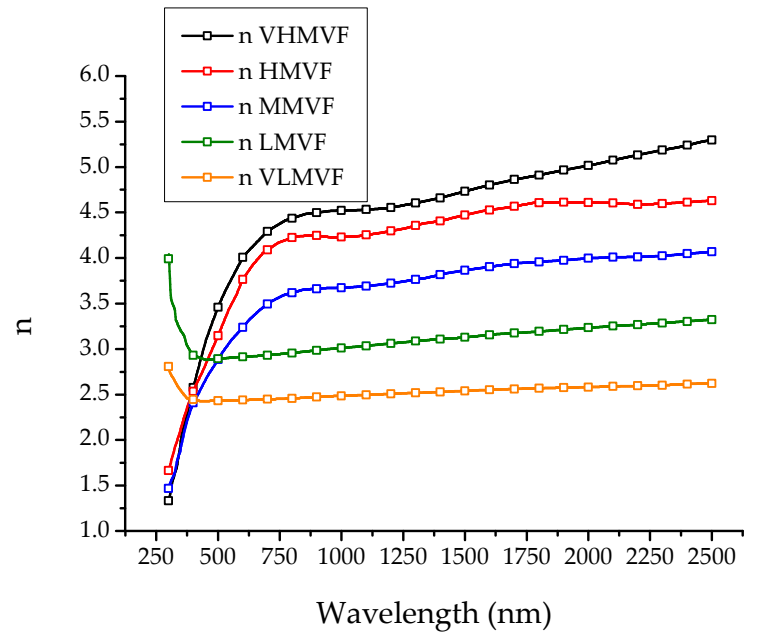

(a)

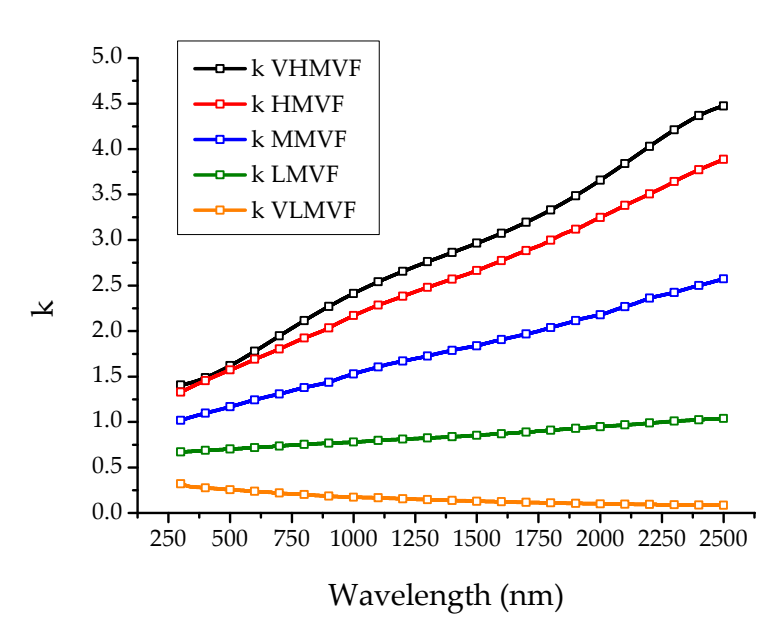

(b)

Figure 4. Optical parameters of the five deposited W-AlN cermet samples. (a) Refractive index n; (b) Extinction coefficient k.

\subsection{AlN and $\mathrm{SiO}_{2}$ Ceramics}

The deposition of $\mathrm{AlN}$ and $\mathrm{SiO}_{2}$ was carried out through the reactive sputtering technique in transition mode. Both deposition processes were conducted at high Ar flow because in these conditions the intensity of the emission spectral line of the selected element varies slowly and the process control is less complex than those conducted at a lower gas flow.

As mentioned in the previous section, AlN deposition was carried out by controlling the $\mathrm{Al}$ emission spectral line because this line showed the highest intensity and the best sensitivity to the target condition variations. Moreover, the same process parameters adopted to deposit the ceramic component of the cermet materials were employed to grow the AlN layer of the AR filter.

Regarding the $\mathrm{SiO}_{2}$ deposition, arcing problems encountered during the reactive sputtering in oxygen atmosphere prevented the application of high-density power to $\mathrm{Si}$ targets [57]. Therefore, the deposition of this ceramic was carried out by controlling the $\mathrm{O}_{2}$ emission spectral line, since it showed the highest intensity and the best sensitivity to target condition variations with the adopted experimental parameters. The $\mathrm{SiO}_{2}$ film with 
the expected optical properties of transparency was deposited by fixing the intensity of the emission spectral line of $\mathrm{O}_{2}$ at $12,000 \mathrm{Cts}$. The evaluated thickness of the $\mathrm{SiO}_{2}$ layer was equal to $148 \mathrm{~nm}$; at the same time, the refractive index $\mathrm{n}$ and the extinction coefficient $\mathrm{k}$, reported in Figure 5, show the typical trends of a ceramic material with a good transparency in correspondence to the solar spectrum.

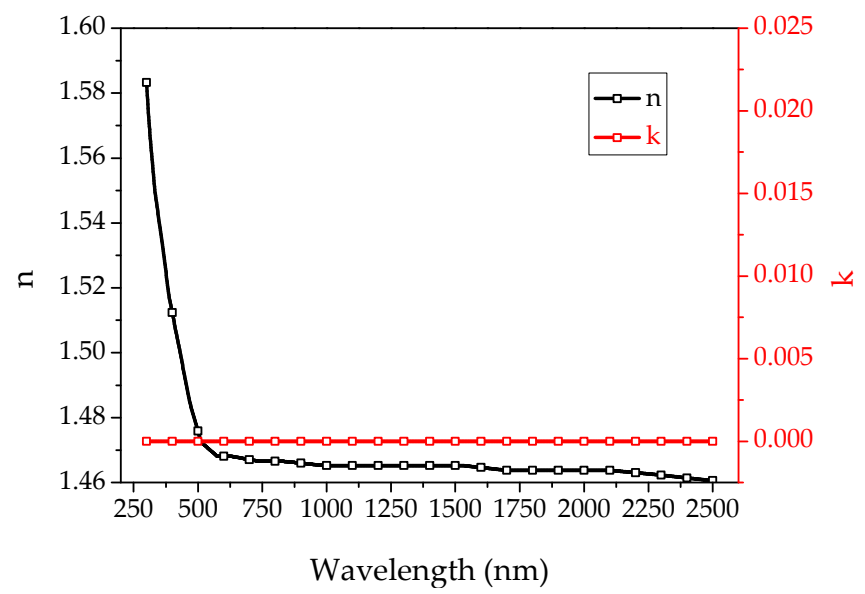

Figure 5. Refractive index $\mathrm{n}$ and extinction coefficient $\mathrm{k}$ of $\mathrm{SiO}_{2}$.

\subsection{Design and Manufacturing of the Solar Coating}

The optical parameters of all materials were collected in a database and imported in Macleod to design the coating with improved thermal stability. Several reflectance curves were simulated in the spectral range $250-2500 \mathrm{~nm}$ by varying the thickness and the metallic profile shape of the graded multilayer cermet, and by combining layers of $\mathrm{AlN}, \mathrm{SiO}_{2}$ and low MVF cermet materials with different thicknesses in the AR filter. This filter has been designed to minimize the reflection of solar radiation by exploiting the interferometry technique; the technique is particularly effective in minimizing the reflection of the solar spectrum when the materials included in the filter show significant difference in the refractive indices. In this case, the low MVF cermet material has a higher refractive index than ceramic materials but, at the same time, has a low absorption coefficient, as small metal volumetric fractions are required to obtain significant increases in the refractive index.

Among the structures simulated by Macleod with $\alpha_{\mathrm{s}}$ included in the range $94 \pm 0.5 \%$, the design with the cut-off at the lowest wavelength and with the highest slope in the transition region was chosen because it had the lowest thermal emittance value for every operating temperature [28]. Table 4 reports the design of the solar coating.

Table 4. Design of the solar coating with improved thermal stability.

\begin{tabular}{ccc}
\hline Material & $\begin{array}{c}\text { Power Density } \\
\left(\mathbf{W} / \mathbf{c m}^{\mathbf{2}}\right)\end{array}$ & $\begin{array}{c}\text { Thickness } \\
(\mathbf{n m})\end{array}$ \\
$\mathrm{W}$ & 13.33 & 120 \\
$\mathrm{Ag}$ & 4.39 & 120 \\
Cermet 1 $(\mathrm{W}, \mathrm{AlN})$ & $(4.89,5.17)$ & 7.94 \\
Cermet 2 $(\mathrm{W}, \mathrm{AlN})$ & $(4.44,5.17)$ & 7.54 \\
Cermet 3 $(\mathrm{W}, \mathrm{AlN})$ & $(4.00,5.17)$ & 7.15 \\
Cermet 4 $(\mathrm{W}, \mathrm{AlN})$ & $(3.56,5.17)$ & 13.5 \\
Cermet 5 $(\mathrm{W}, \mathrm{AlN})$ & $(3.11,5.17)$ & 6.35 \\
Cermet 6 $(\mathrm{W}, \mathrm{AlN})$ & $(2.67,5.17)$ & 5.96 \\
Cermet 7 $(\mathrm{W}, \mathrm{AlN})$ & $(2.22,5.17)$ & 5.56 \\
$\mathrm{AlN}$ & 5.17 & 28.80 \\
Cermet 8 $(\mathrm{W}, \mathrm{AlN})$ & $(1.33,5.17)$ & 9.53 \\
$\mathrm{SiO}$ & 3.88 & 88.80 \\
\hline
\end{tabular}


This coating was manufactured and the experimental reflectance spectrum was measured by UV-Vis-NIR Lambda 950 spectrophotometer and FTIR spectrometer. Figure 6 shows the reflectance of the coating characterized by $\alpha_{\mathrm{s}}$ equal to $93.9 \%$ and $\varepsilon_{\mathrm{th}}$ in the temperature range of $400-550{ }^{\circ} \mathrm{C}$, as reported in Table 5 .

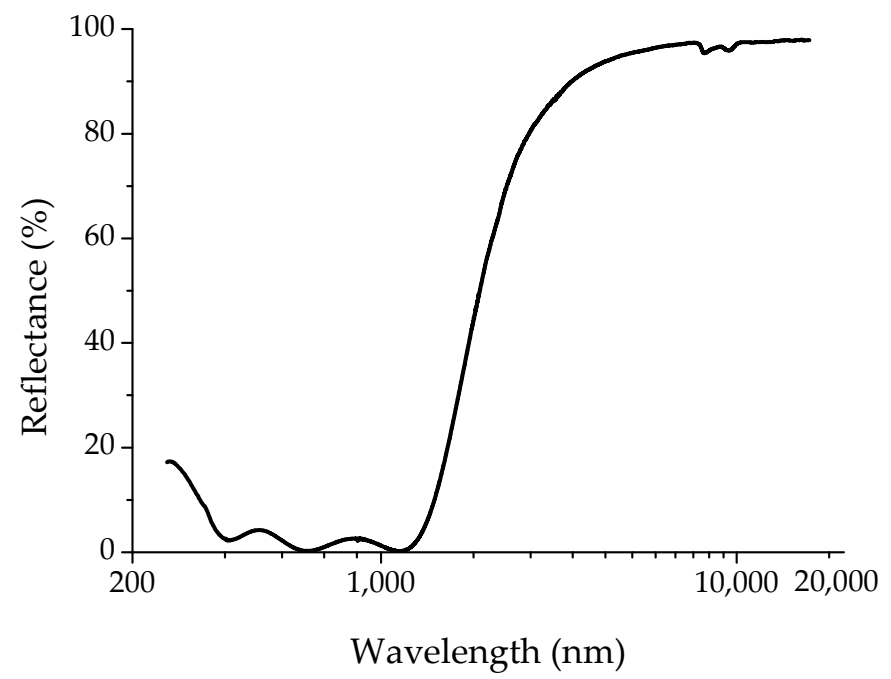

Figure 6. Experimental reflectance of the solar coating with improved thermal stability.

Table 5. $\varepsilon_{\text {th }}$ of the solar coating with improved thermal stability in the temperature range of $400-550{ }^{\circ} \mathrm{C}$.

\begin{tabular}{cc}
\hline $\begin{array}{c}\text { Temperature } \\
\left({ }^{\circ} \mathbf{C}\right)\end{array}$ & $\begin{array}{c}\varepsilon_{\text {th }} \\
\mathbf{( \% )}\end{array}$ \\
\hline 400 & 6.19 \\
450 & 7.04 \\
500 & 8.00 \\
550 & 9.08 \\
\hline
\end{tabular}

\subsection{Durability Study}

In this section, the activity performed to predict the coating lifetime is described. Generally, either the direct or indirect approach can be used to estimate the degradation of a solar coating. The direct approach involves the monitoring of chemical, physical and structural modifications of the coating by means of one or more characterization technique (SEM, TEM, AFM, XRD, RAMAN, SIMS, etc.) after each annealing cycle. Conversely, the indirect approach correlates the chemical, physical and structural modifications of coating with the degradation of some parameters, such as the solar absorptance, hemispherical emittance and photo-thermal conversion efficiency [48-53]. The method developed by ENEA [43] is indirect and consists of the identification of the material degradation mechanisms that contribute to the performance deterioration. Once the main degradation mechanisms are identified, the preponderant degradation factors as well as the critical service conditions influencing the lifetime are known too. Therefore, the degradation rate of the performance parameters can be modeled through a mathematical function and the accelerated test can be performed by increasing the stress conditions through the enhancement of the degradation factors in order to reduce the time to failure. It is worth noting that the correctness of the procedure is guaranteed only if the enhanced degradation factor activates the same degradation mechanisms that are associated to the real working conditions of the coating.

In solar coatings, diffusion and other chemical-physical transformations are the predominant mechanisms activated by temperature that cause the photo-thermal parameters 
degradation. The rate $\mathrm{r}$ of these phenomena can be expressed through the Arrhenius law $[48,49,51-53,58]$ :

$$
r \propto e^{-\left(\frac{E_{a}}{R T}\right)}
$$

where $E_{a}$ is the activation energy, $R$ is the universal gas constant and $T$ is the absolute temperature. Assuming that a linear correlation exists between the rate of the degradation mechanisms and the modification rate of the photo-thermal parameters, the degradation rate of the parameters can be modeled through the Arrhenius law.

Six samples of the same coating were subjected to accelerated ageing tests in a programmable oven to estimate the thermal degradation rate of the photo-thermal parameters, according to the operative conditions specified in the experimental section. The parameters adopted to conduct the durability study were $\alpha_{\mathrm{s}}$ and $\varepsilon_{\text {th }}$ at $500{ }^{\circ} \mathrm{C}$. The three accelerated tests showed that $\alpha_{\mathrm{s}}$ was constant over time because its modifications were negligible compared to the accuracy of the measurement instruments. Differently, according to the Arrhenius law, $\Delta \varepsilon_{\mathrm{th}} / \Delta \mathrm{t}$ was constant over time for each of the three accelerated tests because the difference between the measured value of $\varepsilon_{\text {th }}$ and its corresponding value on the interpolation line was lower than the accuracy of the measurement instruments. Figure $7 \mathrm{a}-\mathrm{c}$ show $\varepsilon_{\text {th }}$ at $500{ }^{\circ} \mathrm{C}$ of the two samples subjected to the accelerated test at $620^{\circ} \mathrm{C}, 650^{\circ} \mathrm{C}$ and $690^{\circ} \mathrm{C}$, respectively, while Figure $7 \mathrm{~d}$ reports the three averaged $\varepsilon_{\text {th }}$ as a function of time. The average values of $\Delta \varepsilon_{\mathrm{th}} / \Delta \mathrm{t}$ calculated on each couple of samples were $1.710^{-3} \mathrm{~h}^{-1}$ at $620^{\circ} \mathrm{C}, 4.5310^{-3} \mathrm{~h}^{-1}$ at $650^{\circ} \mathrm{C}$ and $1.910^{-2} \mathrm{~h}^{-1}$ at $690^{\circ} \mathrm{C}$.

In order to evaluate the maximum operating temperature of the new coating, a $\varepsilon_{\text {th }}$ increase of $1.5 \%$ after 25 years of service ( $8 \mathrm{~h} /$ day) was considered as a good indicator of the long-term stability of the coating. Indeed, it causes a reduction of the photo-thermal conversion efficiency lower than $1.3 \%$ after 25 years in a conventional CSP plant with the parabolic trough collectors that work at an operating temperature of $500{ }^{\circ} \mathrm{C}$. This degradation value was reported in Figure $7 \mathrm{~d}$ and the temporal interval $(\Delta \mathrm{t})$ needed to reach this degradation was evaluated for each accelerated test. In Table 6, these temporal intervals are reported versus the temperatures of the accelerated tests.

At this point, the degradation rate of $\varepsilon_{\text {th }}$ can be expressed through the Arrhenius law as follows:

$$
\frac{\Delta \varepsilon_{\text {th }}}{\Delta \mathrm{t}}=\mathrm{A} \times \mathrm{e}^{-\left(\frac{\mathrm{E}_{\mathrm{a}}}{\mathrm{RT}}\right)}
$$

where $\mathrm{A}$ is the degradation rate constant. If $\Delta \mathrm{t}$ is explicated from Equation (2) and the natural logarithm is computed:

$$
\Delta \mathrm{t}=\frac{\Delta \varepsilon_{\mathrm{th}}}{\mathrm{A}} \times \mathrm{e}^{\frac{\mathrm{E}_{\mathrm{a}}}{\mathrm{RT}}} \Leftrightarrow \ln (\Delta \mathrm{t})=\ln \left(\frac{\Delta \varepsilon_{\mathrm{th}}}{\mathrm{A}}\right)+\frac{\mathrm{E}_{\mathrm{a}}}{\mathrm{RT}}
$$

Equation (3) shows that the temporal interval needed to reach a fixed $\varepsilon_{\text {th }}$ degradation depends only on the operating temperature and its logarithm, plotted against the reciprocal of the temperature, has a linear trend with a slope equal to the ratio $E_{a} / R$. Figure 8 reports the natural logarithm of $\Delta t$ needed to reach a $\varepsilon_{\text {th }}$ degradation of $1.5 \%$ as a function of the reciprocal temperature of each accelerated test. This figure also shows the linear interpolation of these points, which is useful to determine the ratio $E_{a} / R$. 


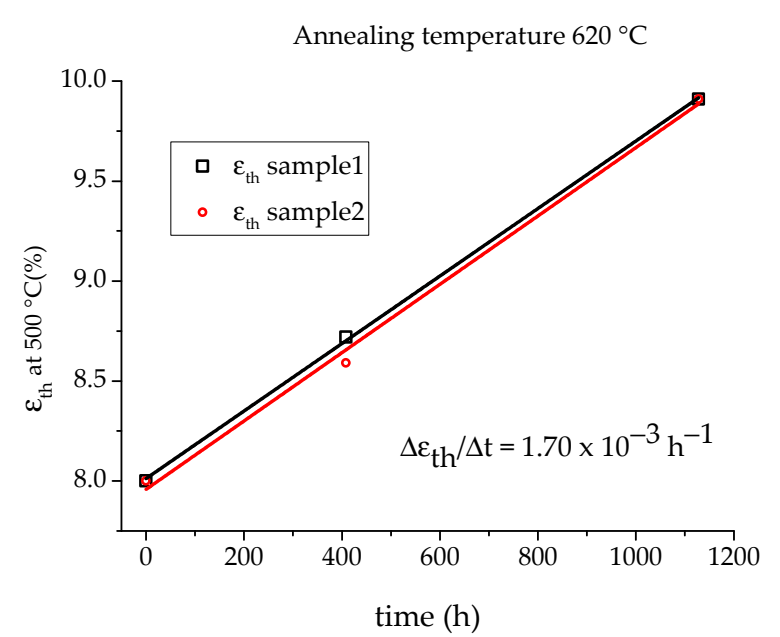

(a)

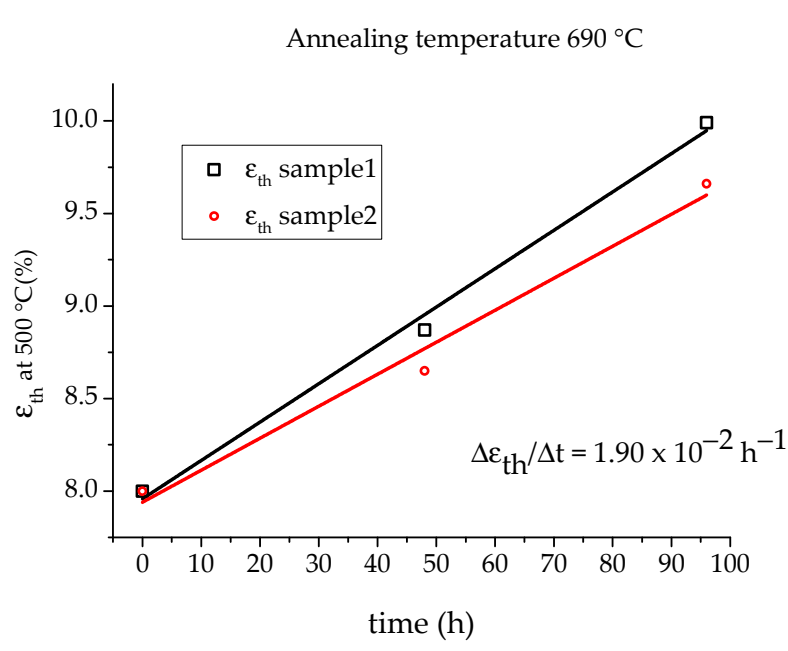

(c)

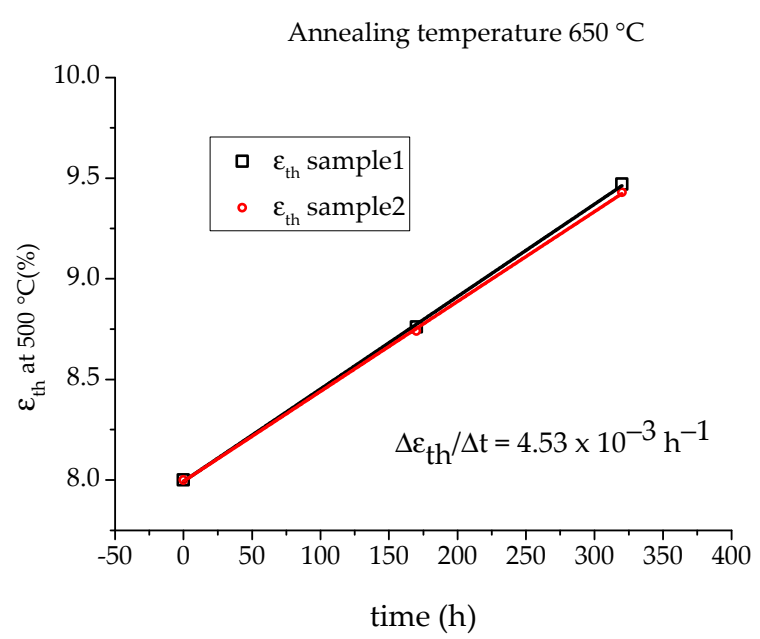

(b)

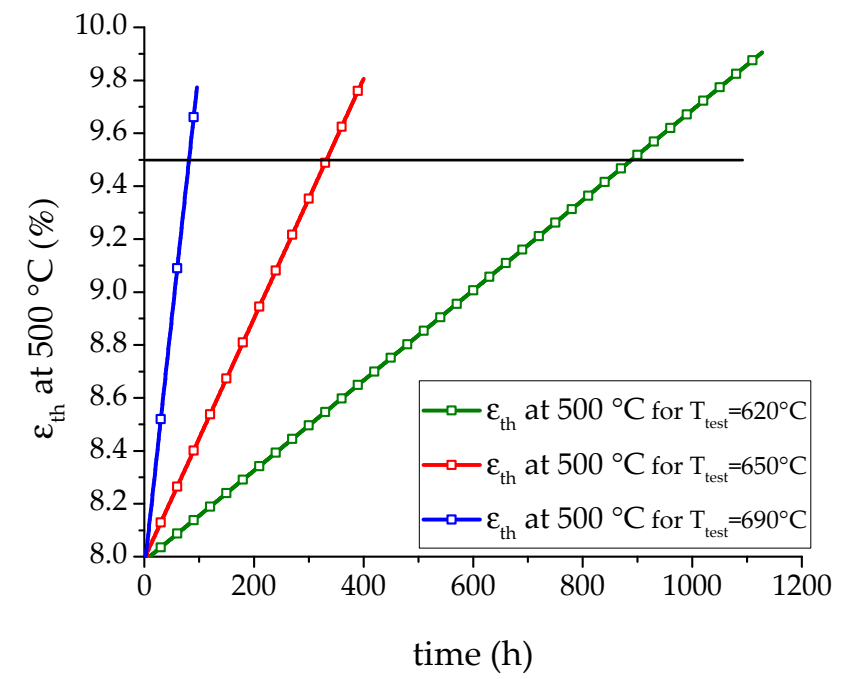

(d)

Figure 7. $\varepsilon_{\text {th }}$ at $500{ }^{\circ} \mathrm{C}$ of the two samples subjected to the accelerated test at different annealing temperatures. (a) $620{ }^{\circ} \mathrm{C}$; (b) $650{ }^{\circ} \mathrm{C}$; (c) $690{ }^{\circ} \mathrm{C}$; (d) averaged $\varepsilon_{\text {th }}$ at $500{ }^{\circ} \mathrm{C}$ as a function of time for the accelerated tests at 620,650 and $690{ }^{\circ} \mathrm{C}$.

Table 6. Temporal intervals needed to reach the $\varepsilon_{\text {th }}$ degradation of $1.5 \%$ versus the temperatures of the accelerated tests.

\begin{tabular}{cc}
\hline $\begin{array}{c}\text { Temperature } \\
\left({ }^{\circ} \mathbf{C}\right)\end{array}$ & $\Delta \mathbf{t}$ \\
$(\mathbf{h})$
\end{tabular}

Although, in principle, only two accelerated tests would be necessary to estimate $\mathrm{E}_{\mathrm{a}}$, the third test was carried out to verify that the modification rate of $\varepsilon_{\text {th }}$ follows the Arrhenius law in the whole range of temperature $620-690^{\circ} \mathrm{C}$.

The $\mathrm{E}_{\mathrm{a}}$ value obtained by the line's slope in Figure 8 was $244 \mathrm{~kJ} / \mathrm{mol}$ and it was used to predict the $\varepsilon_{\text {th }}$ coating degradation after 25 years of service for different operating temperatures. The first prediction was performed at the operating temperature of $400{ }^{\circ} \mathrm{C}$. In this case, the $\varepsilon_{\text {th }}$ degradation after 25 years of service is $0.003 \%$, a value so low to consider invariant the photo-thermal performance of the manufactured coating during its lifetime. The thermal stability improvement of this new coating is still more evident 
if its behavior at $400{ }^{\circ} \mathrm{C}$ is compared with that of the similar coating developed by using the ENEA technology of the double nitride cermet $[26,28]$. The activation energy of this coating was $140 \mathrm{~kJ} / \mathrm{mol}$ and the corresponding increase of $\varepsilon_{\text {th }}$ was $0.18 \%$ after 25 years of service at $400{ }^{\circ} \mathrm{C}$. These data highlight the significant improvement of thermal stability of the new solar coatings. Moreover, it is interesting to observe that a $\varepsilon_{\text {th }}$ increase of $0.18 \%$ is reached by the new coating only after 25 years at $470{ }^{\circ} \mathrm{C}$.

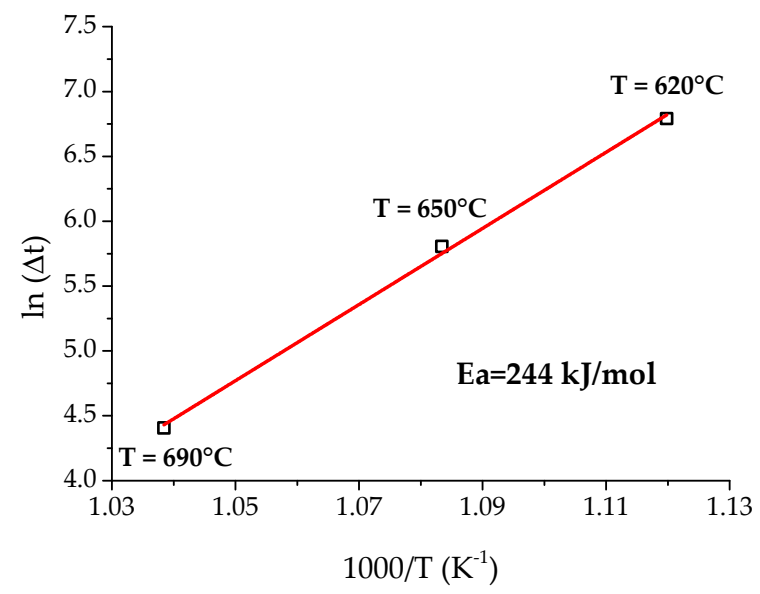

Figure 8. Natural logarithm of the temporal intervals needed to reach a $\varepsilon_{\text {th }}$ degradation of $1.5 \%$ as a function of the reciprocal temperature of each accelerated test.

Finally, Figure 9 shows the temporal interval needed to reach a $\varepsilon_{\text {th }}$ increase of $1.5 \%$ as a function of the operating temperature. Here, the line of the 25 years $(73,000 \mathrm{~h})$ is also reported and the intersection of this line with the curve of the temporal intervals needed to reach a $\varepsilon_{\text {th }}$ increase of $1.5 \%$ identifies the maximum operating temperature of the new coating. This maximum operating temperature is equal to $514{ }^{\circ} \mathrm{C}$. The similar coating developed with the technology of double nitride cermet has a $\varepsilon_{\text {th }}$ increase of $1.5 \%$ after 25 years of service at $463{ }^{\circ} \mathrm{C}$. This result confirms the significant improvement in the stability of the new coating compared to that of similar coatings manufactured by using the previous ENEA technologies.

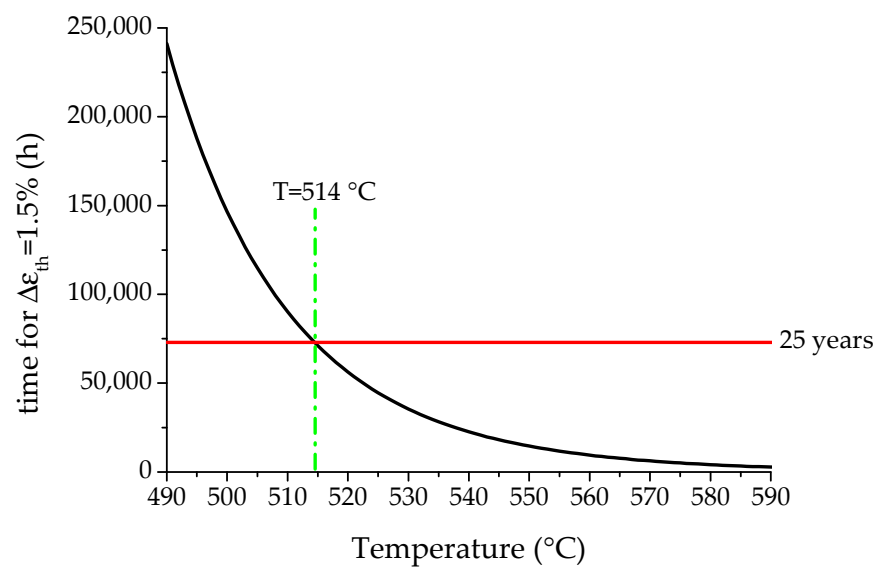

Figure 9. Temporal interval needed to reach a $\varepsilon_{\text {th }}$ increase of $1.5 \%$ as a function of the operating temperature.

\section{Conclusions}

The experimental activity described in this work concerns the manufacturing of a new solar absorber coating, based on an Ag infrared reflector, characterized by high structural and chemical stability under vacuum at high temperature. This new coating was realized through an optimized, high-energy and fast deposition process. The growth of thermally 
stable Ag infrared reflectors was favored by efficient surface pre-treatments of SS substrate and placing the Ag layer between layers of $\mathrm{W}$ and $\mathrm{W}-\mathrm{AlN}$, which were more compact and uniform than those of W and WN-AlN developed by ENEA using the double-nitride cermet technology $[26,28]$. An Unbalanced Magnetron cathode was adopted to promote an ion-assisted deposition process that improved uniformity and compactness of the $\mathrm{W}$ and $\mathrm{W}$-AlN films with respect to $\mathrm{W}$ and $\mathrm{WN}-\mathrm{AlN}$ films deposited with a standard Magnetron cathode. The high deposition rate was obtained by using the DC sputtering technology to deposit all metallic components and the reactive Magnetron sputtering technology in transition mode with MF supply to grow all ceramic components. The multilayer structure of the optimized solar coating with improved thermal stability is composed of the following layers:

SS/W/Ag/graded cermet (W-AlN)/AR filter (AlN, low MVF cermet, $\mathrm{SiO}_{2}$ ).

Five cermet samples were manufactured and optically characterized. The refractive index and extinction coefficient of these samples were used to create a database that, along with the $\mathrm{Ag}$, $\mathrm{AlN}$ and $\mathrm{SiO}_{2}$ optical parameters, was employed to design the solar coating with improved thermal stability. Hence, the new coating was manufactured according to the optimized design and optically characterized to evaluate $\alpha_{\mathrm{s}}$ and $\varepsilon_{\text {th }}$.

Finally, an investigation method developed by ENEA [43] was applied to estimate the degradation of the solar coating at different operating temperatures. This method predicts the lifetime of the manufactured solar coatings by accelerated ageing tests conducted at temperatures above the operating ones, with the aim of experimentally simulating the evolution of the coating over the years. As a first interesting result of this activity, no photo-thermal parameter degradation of the new coating could be observed after 25 years of service at an operating temperature of $400^{\circ} \mathrm{C}$. As a second result, the photothermal conversion efficiency of the new coating decreases by only $1.5 \%$ after 25 years of service at the operating temperature of $514{ }^{\circ} \mathrm{C}$. These findings demonstrate a significant improvement in the long-term thermal stability of the new coating compared to that of similar coatings previously produced by ENEA and justify a further research effort aimed at the identification of more effective structures to stabilize the infrared reflector of $\mathrm{Ag}$. Considering the significant improvement that can be achieved in terms of stability of the tube receiver efficiency through this solar absorber coating, the present results are expected to lead to the reduction of the operative and capital costs of the CSP/CST plants. Indeed, the improved stability and durability of solar coatings will reduce the maintenance costs of the solar field, whereas their enhanced photo-thermal efficiency will impact the solar field global efficiency and, consequently, the solar field size and investment cost.

Author Contributions: Conceptualization, S.E., A.D., C.D. and A.G.; methodology, S.E., A.D., C.D. and A.G.; software, S.E. and A.D.; validation, S.E., A.D. and C.D.; investigation, S.E., A.D., C.D. and G.R.; data curation, A.D., C.D. and G.R.; writing-original draft preparation, S.E.; writing-review and editing, A.D., C.D., A.G., G.R. and M.L.; visualization, S.E., A.D. and C.D.; supervision, M.L. All authors have read and agreed to the published version of the manuscript.

Funding: The results presented in this paper have been obtained in the framework of the project "Concentrating Solar Power", under the "Electric System Research" Program 2019-2021, with the financial support of Italian Ministry for Ecological Transition.

Institutional Review Board Statement: Not applicable.

Informed Consent Statement: Informed consent was obtained from all subjects involved in the study.

Data Availability Statement: The data presented in this study are available on request from the corresponding author. The data are not publicly available since some of the data are linked to research activities carried out within cooperation that were regulated by confidential agreement.

Conflicts of Interest: The authors declare no conflict of interest. 


\section{References}

1. Islama, T.; Huda, N.; Abdullahb, A.B.; Saidur, R. A comprehensive review of state-of-the-art concentrating solar power (CSP) technologies: Current status and research trends. Renew. Sustain. Energy Rev. 2021, 91, 987-1018. [CrossRef]

2. Zhang, H.L.; Baeyens, J.; Degreve, J.; Caceres, G. Concentrated solar power plants: Review and design methodology. Renew. Sustain. Energy Rev. 2013, 22, 466-481. [CrossRef]

3. IRENA (International Renewable Energy Agency). Renewable Power Generation Costs in 2020. Available online: https://www irena.org/-/media/Files/IRENA/Agency/Publication/2021/Jun/IRENA_Power_Generation_Costs_2020.pdf (accessed on 2 September 2021).

4. Reoyo-Prats, R.; Carling Plaza, A.; Faugeroux, O.; Claudet, B.; Soum-Glaude, A.; Hildebrandt, C.; Binyamin, Y.; Agüero, A.; Meißner, T. Accelerated aging of absorber coatings for CSP receivers under real high solar flux-Evolution of their optical properties. Sol. Energy Mater. Sol. Cells 2019, 193, 92-100. [CrossRef]

5. Fuqiang, W.; Ziming, C.; Jianyu, T.; Yuan, Y.; Yong, S.; Linhua, L. Progress in concentrated solar power technology with parabolic trough collector system: A comprehensive review. Renew. Sustain. Energy Rev. 2017, 79, 1314-1328. [CrossRef]

6. Gharat, P.V.; Bhalekar, S.S.; Dalvi, V.H.; Panse, S.V.; Deshmukh, S.P.; Joshi, J.B. Chronological development of innovations in reflector systems of parabolic trough solar collector (PTC)—A review. Renew. Sustain. Energy Rev. 2021, 145, 111002. [CrossRef]

7. Awan, A.B.; Khan, M.N.; Zubair, M.; Bellos, E. Commercial parabolic trough CSP plants: Research trends and technological advancements. Sol. Energy 2020, 211, 1422-1458. [CrossRef]

8. Zhu, G.; Wendelin, T.; Wagner, M.J.; Kutscher, C. History, current state, and future of linear Fresnel concentrating solar collectors. Sol. Energy 2014, 103, 639-652. [CrossRef]

9. Rungasamy, A.E.; Craig, K.J.; Meyer, J.P. A review of linear Fresnel primary optical design methodologies. Sol. Energy 2021, 224, 833-854. [CrossRef]

10. Gharbia, N.E.; Derbal, H.; Bouaichaoui, S.; Saida, N. A comparative study between parabolic trough collector and linear Fresnel reflector technologies. Energy Procedia 2011, 6, 565-572. [CrossRef]

11. Ritchie, I.T.; Window, B. Applications of thin graded-index films to solar absorbers. Appl. Opt. 1977, 16, 1438-1443. [CrossRef]

12. Trotter, D.M.; Sievers, A.J. Spectral selectivity of high-temperature solar absorbers. Appl. Opt. 1980, 19, 711-728. [CrossRef] [PubMed]

13. Zhang, Q.-C.; Mills, D.R. New cermet film structures with much improved selectivity for solar thermal applications. Appl. Phys. Lett. 1992, 60, 545-547. [CrossRef]

14. Zhang, Q.-C.; Mills, D.R. Very low emittance solar selective surfaces using new film structures. J. Appl. Phys. 1992, 72, 3013-3021. [CrossRef]

15. Zhang, Q.-C.; Zhao, K.; Zhang, B.-C.; Wang, L.-F.; Shen, Z.-L.; Lu, D.-Q.; Xie, D.-L.; Zhou, Z.-J.; Li, B.-F. A cylindrical magnetron sputtering system for depositing metal-aluminium nitride cermet solar coatings onto batches of tubes. J. Vac. Sci. Technol. 1998, A16, 628-632. [CrossRef]

16. Zhang, Q.-C. Stainless-steel-AlN cermet selective surfaces deposited by direct current magnetron sputtering technology. Sol. Energy Mater. Sol. Cells 1998, 52, 95-106. [CrossRef]

17. Nunes, C.; Teixeira, V.; Collares-Pereira, M.; Monteiro, A.; Roman, E.; Martin-Gago, J. Deposition of PVD solar absorber coatings for high-efficiency thermal collectors. Vacuum 2002, 67, 623-627. [CrossRef]

18. Farooq, M.; Green, A.A.; Hutchins, M.G. High performance sputtered $\mathrm{Ni}: \mathrm{SiO}_{2}$ composite solar absorber surfaces. Sol. Energy Mater. Sol. Cells 1998, 54, 67-73. [CrossRef]

19. Wang, J.; Wei, B.; Wei, Q.; Li, D. Optical property and thermal stability of $\mathrm{Mo} / \mathrm{Mo}-\mathrm{SiO}_{2} / \mathrm{SiO}_{2}$ solar selective coating prepared by magnetron sputtering. Phys. Status Solidi 2011, A208, 664-669. [CrossRef]

20. Zhang, Q.-C.; Shen, Y.G. High performance W-AlN cermet solar coatings designed by modeling calculations and deposited by DC magnetron sputtering. Sol. Energy Mater. Sol. Cells 2004, 81, 25-37. [CrossRef]

21. Zhang, Q.-C. Recent progress in high-temperature solar selective coatings. Sol. Energy Mater. Sol. Cells 2000, 62, 63-74. [CrossRef]

22. Esposito, S.; Antonaia, A.; Addonizio, M.L.; Aprea, S. Fabrication and optimisation of highly efficient cermet-based spectrally selective coatings for high operating temperature. Thin Solid Films 2009, 517, 6000-6006. [CrossRef]

23. Thornton, J.A.; Lamb, J.L. Sputter deposited $\mathrm{Pt}-\mathrm{Al}_{2} \mathrm{O}_{3}$ selective absorber coatings. Thin Solid Films 1981, 83, 377-385. [CrossRef]

24. Xinkang, D.; Cong, W.; Tianmin, W.; Long, Z.; Buliang, C.; Ning, R. Microstructure and spectral selectivity of $\mathrm{Mo}^{-\mathrm{Al}_{2} \mathrm{O}_{3} \text { solar }}$ selective absorbing coatings after annealing. Thin Solid Films 2008, 516, 3971-3977. [CrossRef]

25. Antonaia, A.; Castaldo, A.; Addonizio, M.L.; Esposito, S. Stability of $\mathrm{W}-\mathrm{Al}_{2} \mathrm{O}_{3}$ cermet based solar coating for receiver tube operating at high temperature. Sol. Energy Mater. Sol. Cells 2010, 94, 1604-1611. [CrossRef]

26. Antonaia, A.; Esposito, S.; Addonizio, M.L.; Guglielmo, A. Solar Selective Absorber Based on Double Nitride Composite Material and Process for Its Preparation. Patent IPN WO/2012/172505, 1 December 2012.

27. Kuckelkorn, T.; Silmy, K.; Dreyer, S. Radiation-Selective Absorber Coating and Absorber Tube with Said Radiation-Selective Absorber Coating. U.S. Patent US S,555,S71 B2, 1 October 2013.

28. Esposito, S.; D'Angelo, A.; Antonaia, A.; Castaldo, A.; Ferrara, M.; Addonizio, M.L.; Guglielmo, A. Optimization procedure and fabrication of highly efficient and thermally stable solar coating for receiver operating at high temperature. Sol. Energy Mater. Sol. Cells 2016, 157, 429-437. [CrossRef]

29. MATS Project. Available online: http:/ / www.mats.enea.it/ (accessed on 9 July 2021). 
30. Weinstein, L.A.; Loomis, J.; Bhatia, B.; Bierman, D.M.; Wang, E.N.; Chen, G. Concentrating solar power. Chem. Rev. 2015, 115, 12797-12838. [CrossRef]

31. Sarvghad, M.; Maher, S.D.; Collard, D.; Tassan, M.; Will, G.; Steinberg, T.A. Materials compatibility for the next generation of concentrated solar power plants. Energy Storage Mater. 2018, 14, 179-198. [CrossRef]

32. Caccia, M.; Tabandeh-Khorshid, M.; Itskos, G.; Strayer, A.R.; Caldwell, A.S.; Pidaparti, S.; Singnisai, S.; Rohskopf, A.D.; Schroeder A.M.; Jarrahbashi, D.; et al. Ceramic-metal composites for heat exchangers in concentrated solar power plants. Nature 2018, 562, 406-409. [CrossRef]

33. Miliozzi, A.; Liberatore, R.; Giannuzzi, G.M.; Veca, E.; Nicolini, D.; Lanchi, M.; Chieruzzi, M. ENEA research and innovation on Thermal Energy Storage for CSP plants. In Proceedings of the 16th CIRIAF National Congress-Sustainable Development, Environment and Human Health Protection, Assisi, Italy, 7-9 April 2016.

34. Wang, X.; Gao, J.; Hu, H.; Zhang, H.; Liang, L.; Javaid, K.; Zhuge, F.; Cao, H.; Wang, L. High-temperature tolerance in WTi-Al ${ }_{2} \mathrm{O}_{3}$ cermet-based solar selective absorbing coatings with low thermal emissivity. Nano Energy 2017, 37, 232-241. [CrossRef]

35. Al-Rjoub, A.; Rebouta, L.; Costa, P.; Vieira, L.G. Multi-layer solar selective absorber coatings based on W/WSiAlN $/ \mathrm{WSiAlO}_{\mathrm{y}} \mathrm{N}_{\mathrm{x}} / \mathrm{SiAlO}_{\mathrm{x}}$ for high temperature applications. Sol. Energy Mater. Sol. Cells 2018, 186, 300-308. [CrossRef]

36. Cao, F.; Kraemer, D.; Sun, T.; Lan, Y.; Chen, G.; Ren, Z. Enhanced thermal stability of W-Ni- $\mathrm{Al}_{2} \mathrm{O}_{3}$ cermet-based spectrally selective solar absorbers with tungsten infrared reflectors. Adv. Energy Mater. 2015, 5, 1401042. [CrossRef]

37. Gao, X.; Wang, C.; Guo, Z.; Geng, Q.; Theiss, W.; Liu, G. Structure, optical properties and thermal stability of $\mathrm{Al}_{2} \mathrm{O}_{3}-\mathrm{WC}$ nanocomposite ceramic spectrally selective solar absorbers. Opt. Mater. 2016, 58, 219-225. [CrossRef]

38. Cao, F.; Tang, L.; Li, Y.; Litvinchuk, A.P.; Bao, J.; Ren, Z. A high-temperature stable spectrally-selective solar absorber based on cermet of titanium nitride in $\mathrm{SiO}_{2}$ deposited on lanthanum aluminate. Sol. Energy Mater. Sol. Cells 2017, 160, 12-17. [CrossRef]

39. Bilokur, M.; Gentle, A.R.; Arnold, M.D.; Cortie, M.B.; Smith, G.B. High temperature optically stable spectrally-selective Ti ${ }_{1-x} \mathrm{Al}_{x} \mathrm{~N}-$ based multilayer coating for concentrated solar thermal applications. Sol. Energy Mater. Sol. Cells 2019, 200, 109964. [CrossRef]

40. Al-Rjoub, A.; Rebouta, L.; Costa, P.; Barradas, N.P.; Alves, E.; Ferreira, P.J.; Abderrafi, K.; Matilainen, A.; Pischow, K. A design of selective solar absorber for high temperature applications. Sol. Energy 2018, 172, 177-183. [CrossRef]

41. Gao, X.; Qiu, X.; Li, X.; Theiss, W.; Chen, B.; Guo, H.; Zhou, T.; Liu, G. Structure, thermal stability and optical simulation of ZrB 2 based spectrally selective solar absorber coatings. Sol. Energy Mater. Sol. Cells 2019, 193, 178-183. [CrossRef]

42. Li, Y.; Lin, C.; Zhou, D.; An, Y.; Li, D.; Chi, C.; Huang, H.; Yang, S.; Tso, C.Y.; Chao, C.Y.H.; et al. Scalable all-ceramic nanofilms as highly efficient and thermally stable selective solar absorbers. Nano Energy 2019, 64, 103947. [CrossRef]

43. Antonaia, A.; D'Angelo, A.; Esposito, S.; Addonizio, M.L.; Castaldo, A.; Ferrara, M.; Guglielmo, A.; Maccari, A. Accelerated aging tests on ENEA-ASE solar coating for receiver tube suitable to operate up to $550{ }^{\circ} \mathrm{C}$. In Proceedings of the AIP Conference Proceedings, 2016, SolarPACES 2016 Conference, Abu Dhabi, United Arab Emirates, 11-14 October 2016; Volume 1734.

44. Antonaia, A.; Addonizio, M.L.; Esposito, S.; Ferrara, M.; Castaldo, A.; Guglielmo, A.; D'Angelo, A. Adhesion and structural stability enhancement for Ag layers deposited on steel in selective solar coatings technology. Surf. Coat. Technol. 2014, 255, 96-101. [CrossRef]

45. Safi, I. Recent aspects concerning DC reactive magnetron sputtering of thin films: A review. Surf. Coat. Technol. 2000, 127, 203-219. [CrossRef]

46. D'Angelo, A.; Diletto, C.; Esposito, S.; Graditi, G.; Guglielmo, A.; Lanchi, M.; Rossi, G. Spectrally selective solar coating based on W-AlN cermet fabricated by reactive sputtering processes at high deposition rate. In Proceedings of the AIP Conference Proceedings, 26th SolarPACES 2020 Conference, on-line, 28 September-2 October 2020. in press.

47. De Sio, A.; Madena, T.; Huber, R.; Parisi, J.; Neyshtadt, S.; Deschler, F.; Da Como, E.; Esposito, S.; Von Hauff, E. Solvent additives for tuning the photovoltaic properties of polymer-fullerene solar cells. Sol. Energy Mater. Sol. Cells 2011, 95, 3536-3542. [CrossRef]

48. Köhl, M.; Gindele, K.; Frei, U.; Häuselmann, T. Accelerated ageing test procedures for selective absorber coatings including life time estimation and comparison without door test results. Sol. Energy Mater. 1989, 19, 257-313. [CrossRef]

49. Brunold, S.; Frei, U.; Carlsson, B.; Möller, K.; Köhl, V. Accelerated life testing of solar absorber coatings: Testing procedure and results. Sol. Energy 2000, 68, 313-323. [CrossRef]

50. Gampp, R.; Oelhafen, P.; Gantenbein, P.; Brunold, S.; Frei, U. Accelerated aging tests of chromium containing amorphous hydrogenated carbon coatings for solar collectors. Sol. Energy Mater. Sol. Cells 1998, 54, 369-377. [CrossRef]

51. Carlsson, B.; Möller, K.; Köhl, M.; Frei, U.; Brunold, S. Qualification test procedure for solar absorber surface durability. Sol. Energy Mater. Sol. Cells 2000, 61, 255-275. [CrossRef]

52. Brunold, S.; Frei, U.; Carlsson, B.; Möller, K.; Köhl, M. Round robin on accelerated life testing of solar absorber surface durability. Sol. Energy Mater. Sol. Cells 2000, 61, 239-253. [CrossRef]

53. Carlsson, B.; Möller, K.; Köhl, M.; Heck, M.; Brunold, S.; Frei, U.; Marechal, J.-C.; Jorgensen, G. The applicability of accelerated life testing for assessment of service life of solar thermal components. Sol. Energy Mater. Sol. Cells 2004, 84, 255-274. [CrossRef]

54. Fujiwara, H. Spectroscopic Ellipsometry Principles and Applications; John Wiley \& Sons Ltd.: Chichester, UK, 2007 ; pp. 189-191.

55. Nadel, S.J.; Greene, P.; Rietzel, J.; Strümpfel, J. Equipment, materials and processes: A review of high rate sputtering technology for glass coating. Thin Solid Films 2003, 442, 11-14. [CrossRef]

56. Musil, J.; Baroch, P.; Vlĉek, J.; Nam, K.H.; Han, J.G. Reactive magnetron sputtering of thin films: Present status and trends. Thin Solid Films 2005, 475, 208-218. [CrossRef] 
57. Kojima, H.; Saito, N.; Takai, O. High-rate reactive deposition of $\mathrm{SiO}_{2}$ films using a new DC rotary sputtering cathode. Surf. Finish. Soc. Jpn. 2012, 63, 179-183. [CrossRef]

58. Kulczyk-Malecka, J.; Kelly, P.J.; West, G.; Clarke, G.C.B.; Ridealgh, J.A. Diffusion studies in magnetron sputter deposited silicon nitride films. Surf. Coat. Technol. 2014, 255, 37-42. [CrossRef] 